This document is the accepted manuscript version of the following article:

F.L.P. Gabriel, E.J. Routledge, A. Heidlberger, D. Rentsch, K. Guenther, W. Giger, J.P. Sumpter, H.-P.E. Kohler (2008). Isomer-specific Degradation and Endocrine Disrupting Activity of Nonylphenols. Environmental Science and Technology, 42, 6399-6408. http://doi.org/10.1021/es800577a 


\section{Isomer-specific Degradation and Endocrine Disrupting Activity of Nonylphenols} 2

3

4 Frédéric L. P. Gabriel ${ }^{1}$, Edwin J. Routledge ${ }^{2}$, Andy Heidlberger ${ }^{1}$, Daniel Rentsch ${ }^{3}$, 5 Klaus Guenther ${ }^{4}$, Walter Giger ${ }^{1}$, John P. Sumpter ${ }^{2}$, and Hans-Peter E. Kohler ${ }^{1 *}$ 6 7

$8 *$ Corresponding author

9

$10{ }^{1}$ Eawag, Swiss Federal Institute of Aquatic Science and Technology, 8600 Dübendorf, 11 Switzerland

$12 \quad{ }^{2}$ Brunel University, Uxbridge, Middlesex UB8 3PH, UK

$13{ }^{3}$ Empa, Swiss Federal Laboratories for Materials Testing and Research, 8600

14 Dübendorf, Switzerland

$15{ }^{4}$ Institute for Chemistry and Dynamics of the Geosphere: Institute 3, Phytosphere,

16 Research Centre Juelich, D-52425 Juelich, Germany

17

18 Corresponding authors e-mail address: kohler@eawag.ch

19

20 Keywords: Nonylphenol, Sphingobium xenophagum Bayram, endocrine disruption,

21 degradation, microbial metabolism, estrogenic activity, ipso-hydroxylation 


\section{$1 \quad$ Abstract}

2 Degradation of technical nonylphenol by Sphingobium xenophagum Bayram led to a

3 significant shift in the isomers composition of the mixture. By means of gas

4 chromatography-mass spectrometry, we could observe a strong correlation between

5 transformation of individual isomers and their $\alpha$-substitution pattern, as expressed by

6 their assignment to one of six mass spectrometric groups. As a rule, isomers with less

7 bulkiness at the $\alpha$-carbon and those with an optimally sized main alkyl chain (4 to 6

8 carbon atoms) were degraded more efficiently. By mass spectrometric analysis, we

9 identified the two most recalcitrant main isomers of the technical mixture (Group 4) as

10 4-(1,2-dimethyl-1-propylbutyl)phenols $\left(\mathrm{NP}_{193 \mathrm{a}}\right.$ and $\left.\mathrm{NP}_{193 \mathrm{~b}}\right)$, which are diastereomers

11 with a bulky $\alpha-\mathrm{CH}_{3}, \alpha-\mathrm{CH}\left(\mathrm{CH}_{3}\right) \mathrm{C}_{2} \mathrm{H}_{5}$ substitution. Our experiments with strain Bayram

12 show that the selective enrichment of isomers with bulky $\alpha$-substitutions observed in

13 NP fingerprints of natural systems can be caused by microbial ipso-hydroxylation.

14 Based on the yeast estrogen assay (YES), we established an estrogenicity ranking with a

15 variety of single isomers and compared it to rankings obtained with different reporter

16 cell systems. Structure-activity relationships derived from these data suggest that Group

174 isomers have a high estrogenic potency. This indicates a substantial risk that

18 enrichment of highly estrogenic isomers during microbial degradation by ipso-

19 substitution will increase the specific estrogenicity of aging material. 


\section{Introduction}

2

3

Nonylphenols (NPs) are well known toxic and endocrine disrupting environmental contaminants formed during microbial degradation of nonylphenol polyethoxylates, an important class of non-ionic surfactants $(1,2)$. Because nonylphenol polyethoxylates are originally synthetized from technical nonylphenol (tNP), the nonylphenol (NP) released during the microbial metabolism of the surfactant is the original technical material. tNP is a complex mixture of more than 100 isomers that differ in the structure and the position of the alkyl moiety attached to the phenol ring (3). More than $90 \%$ of the mixture consists of para-substituted NPs (4-NPs) $(4,5)$. Given the amphiphilic nature and the branched alkyl side chain of NP, it was initially assumed that only bacterial consortia were able to use those compounds for growth (6). Yet in the last few years, several bacterial strains able to grow with tNP as the sole source of carbon and energy and belonging to the Sphingomonad group were isolated from activated sludge of sewage treatment plants (6-9). Surprisingly, these isolates do not metabolize NP by oxidative attack on the alkyl side chain, but rather release the alkyl moiety as a volatile alcohol derivative with unchanged carbon connectivity and most likely utilize only the aromatic ring as a carbon and energy source $(8,10-12)$ (Figure 1, A). Growth experiments with strain Bayram showed that $\alpha$ quaternary NP isomers serve as growth substrates, whereas NPs containing $\alpha$ hydrogens do not. Nevertheless, such isomers are cometabolically transformed to parahydroxylated metabolites with retained alkyl moieties (Figure $1 \mathrm{~B})(8,13)$. These findings, together with elaborate ${ }^{18} \mathrm{O}$ labeling experiments led to the elucidation of a degradation pathway. NPs are hydroxylated at the ipso-position to produce 4-alkyl-4hydroxy-cyclohexa-2,5-dien-1-ones (quinols), from which $\alpha$-quaternary alkyl moieties are able to detach as transient alkyl carbocations (13-15). The electrophilic reaction of 
1 the carbocation with a water molecule then yields the corresponding nonanol (Figure

2 1A). As the carbocation only forms if sufficiently stabilized by $\alpha$-alkyl branching, side

3 chains containing $\alpha$-hydrogens are not released (Figure 1B). This partially explains the

4 divergent biodegradative behavior of NP isomers with different $\alpha$-substitutions.

5

6

7

As early as 1938, it was realized that the phenanthrene ring system in estradiol is not a prerequesite for estrogenic activity. It could be shown that several parasubstituted monophenols (e.g. 4-propenylphenol, 4-tert.-amylphenol, 4cyclohexylphenol) and substances containing two phenol groups joined by a carbon chain (e.g. 4,4'-dihydroxystilbene) mimic the activity of estradiol, causing vaginal cornification in ovariectomized rats (16). But it took almost half a century before it was realized that NP is an estrogenic disruptor $(17,18)$. Recently, estrogenic activities of different NP isomers were shown to vary depending on the structure of the alkyl side chain (19-22). This implies that changes in the isomer composition of NP mixtures will have an effect on the specific estrogenic potency of the material.

In most environmental monitoring studies NP isomeric mixtures have been treated as single compounds. Yet more recently, several investigations showed that the isomeric composition of NP mixtures in natural systems may significantly differ from that of technical mixtures $(19,23-25)$. In certain matrices however, no marked differences were observed (26-29). The finding that strain Bayram differentially degrades nonylphenol isomers, indicates that selective microbial metabolism can lead to changes in the isomer composition of 4-nonylphenol mixtures in the environment (8). Furthermore, during composting of biosolids the transformation of $\alpha$-methyl- $\alpha$-propyl substituted NPs was significantly slower than that of isomers with less bulkiness at the $\alpha$-carbon (25). 
1 Here we show that metabolism of tNP by Sphingobium xenophagum Bayram

2 indeed leads to prominent changes in the isomeric composition. As a rule, isomers with

3 less bulkiness at the $\alpha$-position were degraded faster. This structure-biodegradability

4 relationship is able to explain the formation of the specific NP isomeric patterns

5 observed in complex natural systems $(23,25)$. Furthermore, estrogenicity assays with a

6 wide variety of single NP isomers indicate that differential ipso-hydroxylation of NP

7 mixtures may markedly affect the specific estrogenicity (activity per amount of the

8 mixture) of the aging material.

10 Experimental Section

11 Nonylphenols. The abbreviations used for the various 4-NP isomers are based on

12 the systematic numbering system proposed by Guenther et al. (30). For the sake of

13 simplicity, we did generally not mention the anchor position of the alkyl moiety (e.g.

$14 \quad \mathrm{NP}_{194}$ instead of 4-NP $\left.{ }_{194}\right)$. The technical nonylphenol (tNP) mixtures used in the

15 degradation experiment and the yeast estrogen assay were purchased from Fluka

16 (Buchs, Switzerland; 85\% pure as referred to the amount of para-isomers) and

17 Schenectady International, Inc. (Schenectady, NY, USA; 95\% purity), respectively.

18 Beside of $\mathrm{NP}_{93}, \mathrm{NP}_{194}, \mathrm{NP}_{10}$, and $\mathrm{NP}_{70}$, NPs were $>99 \%$ pure (see Table 2 and

19 Supporting Information).

20 Media and growth conditions. For degradation experiments with tNP we used

$21300 \mathrm{ml}$ Erlenmeyer culture flasks containing each $50 \mathrm{ml}$ of minimal medium and 1

$22 \mathrm{mg} / \mathrm{ml} \mathrm{tNP}$, which was added as described previously (8), except that the solvent was

23 acetone instead of $n$-hexane. We inoculated each flask with $1 \mathrm{ml}$ of a preculture of

24 Sphingobium xenophagum Bayram $\left(\mathrm{OD}_{546}\right.$ of 0.38$)$ that was grown for six days in

minimal medium with $1 \mathrm{mg} / \mathrm{ml} \mathrm{tNP}$ as sole carbon and energy source. Incubation took 
1 place on a rotatory shaker $(250 \mathrm{rpm})$ at $25^{\circ} \mathrm{C}$. To monitor the composition of

2 undegraded NP we set up a series of identical vessels, each being sacrificed at the

3 appropriate day by shock freezing at $-80^{\circ} \mathrm{C}$ (incubation for 9,18 , and 27 days,

4 respectively; at day 9, two vessels were sacrificed instead of one; a control vessel was

5 frozen immediately after starting the incubation). A sterile control was incubated until

6 the end of the experiments. A degradation experiment with strain Bayram and a mixture

7 of the para-isomers $\mathrm{NP}_{194}, \mathrm{NP}_{112}, \mathrm{NP}_{111}, \mathrm{NP}_{152}$, and $\mathrm{NP}_{65}$ was performed in screw cap

8 cylindrical glass culture vials, each containing $3 \mathrm{ml}$ of liquid minimal medium and 1

$9 \mathrm{mg} / \mathrm{ml}$ per isomer as the sole source of carbon and energy (Table S1) (8).

10 Analytical procedures. The frozen cultures were thawed and we added $1.0 \mathrm{mg}$

11 and $500 \mu \mathrm{g}$ of 4-tert.-octylphenol (4-(1,1,3,3-tetramethylbutyl)phenol) dissolved in 2-

12 propanol $(25 \mu \mathrm{l})$ as internal standards to the 50-ml and 3-ml cultures, respectively.

13 Nonylphenol was then extracted thrice (twice in the case of the 3-ml cultures) by

14 vigourously stirring the cultures for 5 min with $20 \mathrm{ml}(2 \mathrm{ml})$ of $\mathrm{CH}_{2} \mathrm{Cl}_{2}$ on a magnetic

15 stirrer. After phase separation an aliquot was withdrawn for GC-MS analysis. Samples

16 were diluted with $\mathrm{CH}_{2} \mathrm{Cl}_{2}$ to obtain appropriate internal standard concentrations.

17 We used a GC 8060 gas chromatograph (Fisons instruments, Milan, Italy) coupled

18 to an MD 800 quadrupole mass spectrometer (Fisons instruments, Manchester, UK) for

19 GC-MS analysis. The injector was operated in splitless mode at $270^{\circ} \mathrm{C}$. Two microliters

20 of the sample were injected by an A200S autosampler (CTC Analytics, Zwingen,

21 Switzerland). Separations were achieved on a DB-17 MS capillary column (60 m, 0.25

$22 \mathrm{~mm}$ internal diameter, 0.25- $\mu \mathrm{m}$ film thickness; J\&W Scientific, Folsom, CA, USA)

23 connected to deactivated pre- and transfer columns (ca. 2 m each). The following

24 gradient program was applied: isothermal at $50^{\circ} \mathrm{C}$ for $1.5 \mathrm{~min}, 10^{\circ} \mathrm{C} / \mathrm{min}$ to $165^{\circ} \mathrm{C}$, and

$250.6^{\circ} \mathrm{C} / \mathrm{min}$ to $175^{\circ} \mathrm{C}$, which was held for $30 \mathrm{~min}$. The interface and source temperatures 
1 were set to 250 and $200^{\circ} \mathrm{C}$, respectively. Ionization was performed by electron impact

$2(70 \mathrm{eV})$. In the experiments with tNP and a mixture of selected nonylphenol isomers,

3 data were acquired in the full scan mode ( $\mathrm{m} / \mathrm{z} 35$ to 271$)$ and by single ion monitoring

$4 \quad(m / z, 107,121,135,149,163,177,191$, and 220), respectively. Peaks in Figure 2 and

5 Table 1 were identified by comparing retention times, TIC peak intensities and

6 fragmentation patterns to published $(5,31)$ and unpublished results $\left(\mathrm{NP}_{36}, \mathrm{NP}_{37}\right.$, and

$7 \quad \mathrm{NP}_{119}$; B. Thiele, V. Heinke, E. Kleist, and K. Guenther) and by cochromatography with

8 available isomers $\left(\mathrm{NP}_{194}, \mathrm{NP}_{36}, \mathrm{NP}_{112}, \mathrm{NP}_{111}, \mathrm{NP}_{152}, \mathrm{NP}_{65}\right.$, and $\left.\mathrm{NP}_{9}\right)$. Our assignments of

$9 \quad \mathrm{NP}_{36}, \mathrm{NP}_{37}$, and $\mathrm{NP}_{119}$ are compatible with the results of Katase et al. (32). The same

10 reference, together with mass spectrometric considerations (not shown), were used to

11 assign peaks 9,29 , and 40 to $\mathrm{NP}_{38}, \mathrm{NP}_{110 \mathrm{a}}$, and $\mathrm{NP}_{110 \mathrm{~b}}$, respectively. We elucidated the

12 structure of Group 4 isomers (peaks 27 and 30) by mass spectrometry (see Supporting

13 Information). To calculate the amount of material remaining after incubation, relative

14 peak areas (4-tert.-octylphenol as reference) at the end of the experiment were divided

15 by those at the start. To quantify groups of isomers and individual isomers the TIC

16 chromatogram and one or two characteristic $\mathrm{m} / \mathrm{z}$ traces, respectively, were examined.

17 Yeast Estrogen Assay (YES). Details of the estrogen-inducible expression

18 system in yeast and preparation of the medium components have been described

19 previously (33). However, in the present study plates were shaken for 2 min before

20 incubation. Assays with dilution series of the test samples were performed in duplicate

21 and included an appropriate number of medium-only blanks. Because in our hands the

22 sensitivity of the YES has increased over the last 12 years, direct comparisons of

23 absolute potencies with those published elsewhere are not meaningful. Here, we

24 compare the potency of individual isomers to that of the mixture (see below). As this is

25 done in the same assay (and on more than one occasion), such data are robust and allow 
1 to appraise if the order of relative potencies resulting from our experiments is consistent

2 with rankings established by others.

3

4 Results and Discussion

5 Aging of technical nonylphenol. Strain Bayram significantly altered the isomer

6 distribution profile of tNP when growing with this substrate as the sole carbon and

7 energy source (Figure 2). It consumed $86 \%$ of the 4-NP isomers (retention time 32.7-

$840.5 \mathrm{~min}$ ) and about $40 \%$ of the presumptive 2-NPs (retention time 25.5-32.6 min)

9 within nine days of incubation. Thereafter degradation ceased, a phenomenon also

10 described for strain TTNP3 (12) and possibly related to the accumulation of chemically

11 reactive 2-nonyl-p-quinones derived from corresponding alkyl-hydroquinone

12 metabolites $(4,13)$. We observed a remarkable correlation between the percentage

13 metabolized of an individual isomer and its substitution pattern at the $\alpha$-carbon,

14 indicated by assignment of the isomer to one of six mass spectrometrical groups.

15 Isomers are classified into those groups according to the set of fragment ions $(\mathrm{m} / \mathrm{z}, 107$,

$16121,135,149,163,177$, and 191) produced by homolytical cleavage of the $\alpha$ -

17 substituents $(5,31)$ (Tables 1 and S1). For Group 4 isomers (peaks 27 and 30, Figure 2),

18 we propose a structure $\left(\mathrm{NP}_{193 \mathrm{a}}\right.$ and $\mathrm{NP}_{193 b}$, pair of diastereomers) that accounts for the

19 characteristic mass spectrum, which displays intensive peaks at $m / z 163,121$, and 107 ,

20 and smaller peaks at $m / z, 177,161,147,134,133$. Our structure assignments accord

21 with those recently published by Katase et al., which are based on ${ }^{1} \mathrm{H}-$ and ${ }^{13} \mathrm{C}-\mathrm{NMR}$

22 analysis (32) (see Supporting Information).

23 The percentage that was metabolized ranged from $31 \%$ in the case of the isomers

2427 and 30 (Group 4) to about $100 \%$ for the $\alpha, \alpha$-dimethyl isomers (Group 1) (Table 1).

25 Group 5 isomers ( $\alpha$-methyl, $\alpha$-n-propyl) proved to be more recalcitrant than Group 2 
1 isomers ( $\alpha$-methyl, $\alpha$-ethyl). Results of a degradation experiment with a mixture of

2 selected $\alpha$-quaternary $4-\mathrm{NP}$ isomers as substrates confirmed these findings. In this

3 experiment the sequence of percentage metabolized $\left(\mathrm{NP}_{112}>\mathrm{NP}_{111 \mathrm{a}}>\mathrm{NP}_{111 \mathrm{~b}}>\mathrm{NP}_{65}>\right.$

$4 \quad \mathrm{NP}_{194} \cong \mathrm{NP}_{152}$, Table S1) matched that from the experiment with tNP (Table 1).

5 Differential degradation of NP isomers is most likely caused by ipso-

6 hydroxylation rates that vary between the isomers, and not so much by the ability of the

7 alkyl moiety to detach as a carbocation. Inability to detach would result in an

8 accumulation of the cyclohexadienone intermediates with subsequent formation of dead

9 end metabolites (Figure 1B) (13) but should not be the cause for differential degradation

10 of NP isomers in a mixture. The degradation ranking established for differential

11 metabolism of tNP by strain Bayram shows that degradation was more effective when

12 the $\alpha$-position was less bulky: $\alpha-\left(\mathrm{CH}_{3}\right)_{2}\left(\mathrm{Group} \mathrm{1)}>\alpha-\mathrm{CH}_{3}, \alpha-\mathrm{CH}_{2} \mathrm{CH}_{3}(\mathrm{Group} 2)>\alpha-\right.$

$13 \mathrm{CH}_{3}, \alpha-\mathrm{CH}_{2} \mathrm{CH}_{3}, \beta-\mathrm{CH}_{3}\left(\right.$ Group 3) $>\alpha-\mathrm{CH}_{3}, \alpha-\mathrm{CH}_{2} \mathrm{CH}_{2} \mathrm{CH}_{3}\left(\right.$ Group 5) $>\alpha-\mathrm{CH}_{3}, \alpha-$

$14 \mathrm{CH}\left(\mathrm{CH}_{3}\right)_{2}\left(\right.$ Group 6) $>\alpha-\mathrm{CH}_{3}, \alpha-\mathrm{CH}\left(\mathrm{CH}_{3}\right) \mathrm{C}_{2} \mathrm{H}_{5}$ (Group 4) (Table 1) (for convenience,

15 the $\alpha-\mathrm{CH}\left(\mathrm{CH}_{3}\right) \mathrm{C}_{2} \mathrm{H}_{5}$ and the $\alpha-\mathrm{CH}_{2} \mathrm{CH}_{2} \mathrm{CH}_{3}$ branches of Group 4 isomers are viewed as

$16 \alpha$-substituent and part of the main chain, respectively).

17 The NP ipso-hydroxylase activity of strain Bayram has been grouped with the

18 flavin monooxygenase enzyme family (9). Hence, we would expect an electrophilic

19 oxygen species as hydroxylating agent. Bulky $\alpha$-alkyl substituents enhance the electron

20 density at the ipso-position and, therefore, should facilitate the electrophilic addition of

21 that oxygen species. However, the opposite is observed. From these results we conclude

22 that ipso-hydroxylation rates are most likely governed by steric rather than by electronic

23 effects. On the one hand, bulky $\alpha$-alkyl substituents sterically hinder hydroxylation at

24 the neighboring ipso-position and on the other hand they electronically promote the

25 cleavage of the alkyl moiety once the quinol intermediate has been formed (8). The 
1 length of the main alkyl chain also seems to play an important steric role, because

2 isomers with little bulkiness at the $\alpha$-position but lengthy alkyl chains $\left(\mathrm{NP}_{9}, \mathrm{NP}_{2}\right.$ and

$3 \quad \mathrm{NP}_{1}$ ) are relatively slowly transformed (Table 1 , Figure $\left.1 \mathrm{~B}\right)(8)$.

NP fingerprints. Differential microbial metabolism of tNP mixtures in the

5 environment will ultimately lead to changes in the relative composition of aged

6 material. Unraveling the principles that govern the reshaping of isomer distribution

7 patterns will help us to understand how certain isomeric fingerprints observed in natural

8 systems have formed. Indeed, careful analysis of isomer distribution patterns in river

9 water samples at different locations around Tokyo Bay (23), leads to the hypothesis that

10 the nonylphenol contaminants underwent microbial degradation by ipso-substitution

11 (Figures S2, S3, S4). In this context, it is interesting to note that Sphingomonas cloacae,

12 one of the first strains known to degrade NPs by detaching the alkyl side chain, was

13 isolated at a sewage-treatment plant in Tokyo, i.e. in close proximity of the sampling

14 sites (7). Furthermore, an ipso-substitution degradation mechanism may be called upon

15 to explain the relative enrichment of NPs with a bulky $\alpha$-substitution during composting

16 of biosolids (25).

17 We believe that different environmental matrices are characterized by distinct

18 isomeric fingerprints that depend on the grade of aging and on the dominating aging

19 process (e.g. metabolism by specific NP degrading microbial communities). In certain

20 matrices, when transformation processes with little discrimination between individual

21 isomers prevail (ortho-hydroxylation may be an example), or when transformation

22 processes are absent, NP fingerprints will be similar to those of technical mixtures.

23 Diminished bioavailability by rapid adsorption to solids may explain the lack of

24 isomeric shifts reported for some sediment $(27,28)$. Changes of isomeric fingerprints

25 will be less obvious in systems such as aerobic basins of sewage treatment plants (29), 
1 in which the rate of formation of NP from NP polyethoxylates is much higher than the 2 rate of degradation of NP.

Estrogenicity of NP isomers. All NP samples were assayed over a concentration range of $0.13 \mathrm{mM}$ down to $0.24 \mu \mathrm{M}$. Figure 3 shows the response of the yeast estrogen screen (YES) to various concentrations of each NP sample. The NP isomers generally produced full dose response curves over a range of two orders of magnitude, with the most potent isomer $\left(\mathrm{NP}_{93}\right)$ being only 1690 times less potent than $17 \beta$-estradiol, and nearly twice as potent as the technical mixture of isomers (Figure 3, Table 2).

A pioneering study of the structural properties of alkylphenols that are associated with estrogenic activity concluded that the branching on the $\alpha$-carbon may be an important feature for estrogenic activity (34). Since all the isomers at our disposal were $\alpha$-substituted, and because a difference in estrogenicity of two isomers inherently can be interpreted by positive and negative effects (Table 3), we could not derive a unequivocal correlation between $\alpha$-substitution pattern and estrogenicity from our data. However, isomers that can be derived from a particular $\alpha$-substituted isomer by shifting bulky groups that surround the $\alpha$-position partly or entirely to the $\beta$ - or $\gamma$-position always showed higher activities (compare $\mathrm{NP}_{9}$ with $\mathrm{NP}_{10}, \mathrm{NP}_{65}$ with $\mathrm{NP}_{70}, \mathrm{NP}_{112}$ with $\mathrm{NP}_{93} / \mathrm{NP}_{95}, \mathrm{NP}_{152}$ with $\mathrm{NP}_{111}$, Table $3 \mathrm{~A}-\mathrm{D}$, respectively). These data can be explained by a positive effect of $\beta$ - and $\gamma$-substituents, by a negative effect of bulkiness at the $\alpha$ position, or by a positive effect of distributing $\alpha$-centered bulkiness along the proximal part of the main chain. The two most potent isomers, $\mathrm{NP}_{93}$ and $\mathrm{NP}_{70}$, both have a $\beta$-alkyl branch and a main chain length of 5 and 6 carbon atoms, respectively. Isomers with a similar chain length (4 to 6 carbon atoms) but without $\beta$-substituents $\left(\mathrm{NP}_{65}, \mathrm{NP}_{111}\right.$, $\left.\mathrm{NP}_{112}, \mathrm{NP}_{152}, \mathrm{NP}_{170}, \mathrm{NP}_{194}\right)$ and isomers with $\beta$-substituents but with a longer chain length $\left(\mathrm{NP}_{10}\right)$ only reached medium levels of estrogenicity (relative potency $\left.0.80-0.25\right)$, 
1 even though they have a quaternary $\alpha$-carbon. This suggests that not $\alpha$-substitution, but

$2 \beta$-substitution together with an optimal length of the main chain is the key for high

3 estrogenic activity. Lack of both of these structural characteristics resulted in very low

4 activities (relative potencies $<0.04$ for $\mathrm{NP}_{9}, \mathrm{NP}_{2}$, and $\mathrm{NP}_{1}$ ).

5 Despite the difference of reporter cell systems used, and except for $\mathrm{NP}_{152}$, our

6 estrogenicity ranking was identical to those established by Shioji et al. and Preuss et al.

7 (Table 2) $(21,22)$. Kim et al. found a divergent ranking for $\mathrm{tNP}, \mathrm{NP}_{152}, \mathrm{NP}_{65}$, and $\mathrm{NP}_{9}$,

8 although they used the same test system as we did $(19,20)$. However, they did not

9 synthesize pure test isomers, but purified them from tNP by preparative HPLC, a

10 procedure that probably leads to significant contamination with other NP isomers (21).

11 Unfortunately, one of the samples that showed highest estrogenicity $\left(\mathrm{NP}_{70}\right)$ in our test

12 system was contaminated with small amounts of eight other 4-NP isomers and several

13 other, non-estrogenic compounds. However, since all of the NP contaminants contained

14 a tertiary $\alpha$-carbon atom, our conclusion that quaternary $\alpha$-carbons are not essential for

15 high estrogenicity remains unaffected (Supporting Information).

16 In agreement with Shioji et al., we favor the hypothesis that an optimal length of

17 the main alkyl chain (4 to 6 carbon atoms) and bulkiness around the $\beta$ - and $\gamma$-position is

18 needed for NP isomers to exhibit high estrogenicity, whereas the presence of $\alpha$ -

19 substituents is less important (17 $\beta$-estradiol itself contains a tertiary $\alpha$-carbon in para-

20 position, not a quaternary one). To explain the positive effect of $\beta$-substituents, it was

21 suggested that a $\beta$-anchored alkyl branch might interact with a cavity of the estrogen

22 receptor $(\mathrm{ER})$, located around the $\mathrm{C}$ ring of $17 \beta$-estradiol $\left(\mathrm{E}_{2}\right)$ in the $\mathrm{ER}-\mathrm{E}_{2}$ complex

23 (22). Although the length and breadth of the $\mathrm{E}_{2}$ skeleton are well matched by the

24 receptor, there are indeed large unoccupied cavities adjacent to the $7 \alpha$ - and $11 \beta$ -

25 positions of $\mathrm{E}_{2}(35,36)$. These cavities allow appropriately positioned steric groups of 
1 certain sizes to fit, and are of great importance for binding xenoestrogens, including

2 DES-like chemicals, diphenylmethanes, and biphenyls (36).

Structure-property relationships. Growth experiments with strain Bayram and

4 yeast estrogen assays (YES) showed that a lengthy main alkyl chain had a negative

5 effect on degradability as well as estrogenic potency of a NP isomer. Because alkyl

6 moieties with lengthy main chains intrinsically tend to have little branching, our former

7 conclusion that the more highly branched the alkyl substituent the faster it degrades,

8 still holds as a general principle (8). However, the rule does not hold for isomers that

9 have bulky substituents at the $\alpha$-position. Indeed, $\alpha$-substitution appears to have a

10 profound effect on ipso-hydroxylation rates, as isomers with increased bulkiness around

11 the $\alpha$-position tended to be more recalcitrant. This applies well to the newly identified

$12 \mathrm{NP}$ isomers $\mathrm{NP}_{193 \mathrm{a}}$ and $\mathrm{NP}_{193 \mathrm{~b}}$ (Group 4), which have bulky $\alpha-\mathrm{CH}_{3}, \alpha-\mathrm{CH}\left(\mathrm{CH}_{3}\right) \mathrm{C}_{2} \mathrm{H}_{5}$

13 substitutions and among the main isomers in tNP are the most recalcitrant. Because

$14 \mathrm{NP}_{119}, \mathrm{NP}_{193 \mathrm{a}}$, and $\mathrm{NP}_{193 \mathrm{~b}}$ are characterized by a $\beta$-alkyl substituent and an optimal size

15 of the main chain, we expect these isomers to have a high estrogenic potency. However,

16 Kim et al. recently reported that in contrast to $\mathrm{NP}_{119}, \mathrm{NP}_{193}$ did not show any estrogenic

17 activity at all. It needs to be noted though, that the tested compounds were isolated from

18 tNP by fractionation with HPLC and GC-PFC, which may affect their purity (19). If this

19 somewhat surprising result is verified, one will have to conclude that in certain

20 nonylphenol isomers, bulky $\alpha$-substitutions have a negative effect on estrogenicity (“4-

21 (di-t-butylmethyl)phenol" however, is highly estrogenic (22)).

22 Estrogenicity of tNP mixtures and the effect of aging. Among the 18 main NP

23 isomers of tNP (Table 1), 11 isomers have been synthetized and tested for estrogenicity

24 so far (this study, (22)). All these isomers were less estrogenic than the technical

25 mixture. These findings imply that certain main isomers that have not been tested yet 
1 for estrogenicity are at least moderately more estrogenic than the technical mixture or,

2 alternatively, that certain minor isomers are highly estrogenic. For instance, it needs to

3 be shown whether highly estrogenic isomers, such as 4-(1,2,2,3,3-

4 pentamethylbutyl)phenol $\left(\mathrm{NP}_{167}\right)$, that appears to be 153 times more potent than $\mathrm{tNP}$

5 (22), are minor components of tNP. Obviously, it would not require much of such an

6 isomer in a technical mixture to account for the latter's estrogenicity. Differential

7 degradation of tNP mixtures certainly affects their specific estrogenicity (activity per

8 amount of the mixture), although the degree and the quality of this effect cannot be fully

9 estimated yet. But it is clear that if highly estrogenic isomers, such as $\mathrm{NP}_{167}$, prove to be

10 recalcitrant components of technical mixtures, then there is a substantial risk that

11 microbial degradation by ipso-substitution will increase the specific estrogenicity of the

12 material.

13 Further research on the varying isomer composition and estrogenicity of NP

14 mixtures during microbial degradation will be needed to show whether certain highly

15 estrogenic isomers are recalcitrant and whether increasing specific estrogenicity is

16 important with regard to risk assessment of aged tNP mixtures.

18 Acknowledgements

19 This research was supported by the Swiss National Science Foundation within the

20 framework of the National Research Programme NFP50 'Endocrine Disruptors:

21 Relevance to Humans, Animals, and Ecosystems'. We thank Dr. Ian Purvis and others at

22 GlaxoSmithKline for kindly supplying the genetically modified yeast strain.

24 Supporting Information Available 
1 In the SI section, we present a detailed analysis of the GC-MS chromatograms of

2 tNP and aged tNP, and of the NP isomer patterns observed by Horii et al. in

3 contaminated river water around Tokyo Bay (23). We also show the results of a

4 degradation experiment with strain Bayram and a defined mixture of NP isomers.

5 Extraction efficiencies are mentioned. Furthermore, we present a detailed analysis of

6 impurities in the $\mathrm{NP}_{10}$ and $\mathrm{NP}_{70}$ samples, and a structural proposal for Group 4 isomers.

7 This information is available free of charge via the Internet at http://pubs.acs.org.

\section{$9 \quad$ Literature Cited}

10 (1) Servos, M. R. Review of the aquatic toxicity, estrogenic responses and

11 bioaccumulation of alkylphenols and alkylphenol polyethoxylates. Water Qual.

12 Res. J. Canada 1999, 34, 123-177.

13 (2) Montgomery-Brown, J.; Reinhard, M. Occurence and behavior of alkylphenol

14 polyethoxylates in the environment. Environ. Eng. Sci. 2003, 20, 471-486.

15 (3) Ieda, T.; Horii, Y.; Petrick, G.; Yamashita, N.; Ochiai, N.; Kannan, K. Analysis of 16 nonylphenol isomers in a technical mixture and in water by comprehensive two-

17 dimensional gas chromatography-mass spectrometry. Environ. Sci. Technol. 2005, $18 \quad 39,7202-7207$.

19 (4) Kohler, H.-P. E.; Gabriel, F. L. P.; Giger, W. ipso-Substitution - A novel pathway

20 for microbial metabolism of endocrine-disrupting 4-nonylphenols, 4-

21 alkoxyphenols, and bisphenol A. Chimia 2008, 62, 358-363.

22 (5) Wheeler, T. F.; Heim, J. R.; LaTorre, M. R.; Janes, A. B. Mass spectral

23 characterization of $p$-nonylphenol isomers using high-resolution capillary GC-MS.

24 J. Chromatogr. Sci. 1997, 35, 19-30. 
1 (6) Tanghe, T.; Dhooge, W.; Verstraete, W. Isolation of a bacterial strain able to degrade branched nonylphenol. Appl. Environ. Microbiol. 1999, 65, 746-751.

(7) Fujii, K.; Urano, N.; Ushio, H.; Satomi, M.; Kimura, S. Sphingomonas cloacae sp. nov., a nonylphenol-degrading bacterium isolated from wastewater of a sewagetreatment plant in Tokyo. Int. J. Syst. Evol. Microbiol. 2001, 51, 603-610.

(8) Gabriel, F. L. P.; Giger, W.; Guenther, K.; Kohler, H.-P. E. Differential Degradation of Nonylphenol Isomers by Sphingomonas xenophaga Bayram. Appl. Environ. Microbiol. 2005, 71, 1123-1129.

(9) Porter, A. W.; Hay, A. G. Identification of $\operatorname{odpA}$, a gene involved in biodegradation of the endocrine disrupter octylphenol. Appl. Environ. Microbiol. 2007, 73, 73737379.

(10) Fujii, K.; Urano, N.; Ushio, H.; Satomi, M.; Iida, H.; Ushio-Sata, N.; Kimura, S. Profile of a nonylphenol-degrading microflora and its potential for bioremedial applications. J. Biochem. 2000, 128, 909-916.

(11) Tanghe, T.; Dhooge, W.; Verstraete, W. Formation of the metabolic intermediate 2,4,4,-trimethyl-2-pentanol during incubation of a Sphingomonas sp. strain with the xeno-estrogenic octylphenol. Biodegradation 2000, 11, 11-19.

(12) Corvini, P. F. X.; Vinken, R.; Hommes, G.; Schmidt, B.; Dohmann, M. Degradation of the radioactive and non-labelled branched 4(3',5'-dimethyl-3'heptyl)-phenol nonylphenol isomer by Sphingomonas TTNP3. Biodegradation 2004, 15, 9-18.

(13) Gabriel, F. L. P.; Heidlberger, A.; Rentsch, D.; Giger, W.; Guenther, K.; Kohler, H.-P. E. A novel metabolic pathway for degradation of 4-nonylphenol environmental contaminants by Sphingomonas xenophaga Bayram. ipso- 
1 Hydroxylation and intramolecular rearrangement. J. Biol. Chem. 2005, 280,

2

3

4 15526-15533.

(14) Corvini, P. F. X.; Hollender, J.; Ji, R.; Schumacher, S.; Prell, J.; Hommes, G.; Priefer, U.; Vinken, R.; Schäffer, A. The degradation of $\alpha$-quaternary nonylphenol isomers by Sphingomonas sp. strain TTNP3 involves a type II ipso-substitution mechanism. Appl. Microbiol. Biotechnol. 2006, 70, 114-122.

(15) Gabriel, F. L. P.; Cyris, M.; Jonkers, N.; Giger, W.; Guenter, K.; Kohler, H.-P. E. Elucidation of the ipso-substitution mechanism for side chain cleavage of $\alpha$ quaternary 4-nonylphenols and 4-t-butoxyphenol in Sphingobium xenophagum Bayram. Appl. Environ. Microbiol. 2007, 73.

(16) Dodds, E. C.; Lawson, W. Molecular structure in relation to oestrogenic activity. Compounds without a phenanthrene nucleus. Proc. R. Soc. B 1938, 125, 222-232.

(17) Soto, A. M.; Justicia, H.; Wray, J. W.; Sonnenschein, C. p-Nonyl-phenol: an estrogenic xenobiotic released from "modified" polystyrene. Environ. Health Perspect. 1991, 92, 167-173.

(18) Warhust, A. M. An environmental assessment of alkylphenol ethoxylates and alkyphenols. Friends of the Earth, Scotland 1995, 1-15.

(19) Kim, Y.-S.; Katase, T.; Harii, Y.; Yamashita, N.; Makino, M.; Uchiyama, T.; Fujimoto, Y.; Inoue, T. Estrogen equivalent concentration of individual isomerspecific 4-nonylphenol in Ariake sea water. Mar. Pollut. Bull. 2005, 51, 850-856.

(20) Kim, Y.-S.; Katase, T.; Sekine, S.; Inoue, T.; Makino, M.; Uchiyama, T.; Fujimoto, Y.; Yamashita, N. Variation in estrogenic activity among fractions of a commercial nonylphenol by high performance liquid chromatography. Chemosphere 2004, 54, $1127-1134$. 
1 (21) Preuss, T. G.; Gehrhardt, J.; Schirmer, K.; Coors, A.; Rubach, M.; Russ, A.; Jones,

(22) Shioji, H.; Tsunoi, S.; Kobayashi, Y.; Shigemori, T.; Ike, M.; Fujita, M.; Miyaji, Y.; Tanaka, M. Estrogenic activity of branched 4-nonylphenol isomers examined by yeast two-hybrid assay. J. Health Sci. 2006, 52, 132-141.

(23) Horii, Y.; Katase, T.; Kim, Y.-S.; Yamashita, N. Determination of individual nonylphenol isomers in water samples by using relative response factor method. Bunseki Kagaku 2004, 53, 1139-1147.

(24) Räcker, T. Bestimmung von Estrogen-aktiven Nonylphenolen und Octylphenol in Säuglings- und Kleinkindernahrung sowie in Biofilmen. Doctoral Thesis, Mathematisch-Naturwissenschaftliche Fakultät, Rheinische Friedrich-WilhelmsUniversität Bonn 2004.

(25) Das, K. C.; Xia, K. Transformation of 4-nonylphenol isomers during biosolids composting. Chemosphere 2008, 70, 761-768.

(26) Topp, E.; Starratt, A. Rapid mineralization of the endocrine-disrupting chemical 4nonylphenol in soil. Environ. Toxicol. Chem. 2000, 19, 313-318.

(27) Isobe, T.; Nishiyama, H.; Nakashima, A.; Takada, H. Distribution and behavior of nonylphenol, octylphenol, and nonylphenol monoethoxylate in Tokyo metropolitan area: their association with aquatic particles and sedimentary distributions. Environ. Sci. Technol. 2001, 35, 1041-1049.

(28) Peng, X.; Wang, Z.; Mai, B.; Chen, F.; Chen, S.; Tan, J.; Yu, Y.; Tang, C.; Li, K.; Zhang, G.; Yang, C. Temporal trends of nonylphenol and bisphenol A contamination in the Pearl River Estuary and the adjacent South China Sea recorded by dated sedimentary cores. Sci. Total. Environ. 2007, 2007, 393-400. 
1 (29) Babay, P. A.; Romero Ale, E. E.; Itria, R. F.; Becquart, E. T.; Thiele, B.; Batistoni, D. A. Simplified determination of lipophilic metabolites of nonylphenol ethoxylates: method development and application in aqueous samples from Buenos Aires, Argentina. J. Environ. Monit. 2008, 10, 443-452.

(30) Guenther, K.; Kleist, E.; Thiele, B. Estrogen-active nonylphenols from an isomerspecific viewpoint: a systematic numbering system and future trends. Anal. Bioanal. Chem. 2006, 384, 542-546.

(31) Thiele, B.; Heinke, V.; Kleist, E.; Guenther, K. Contribution to the structural elucidation of 10 isomers of technical p-nonylphenol. Environ. Sci. Technol. 2004, 38, 3405-3411.

(32) Katase, T.; Okuda, K.; Kim, Y.-S.; Eun, H.; Takada, H.; Uchiyama, T.; Saito, H.; Makino, M.; Fujimoto, Y. Estrogen equivalent concentration of 13 branched paranonylphenols in three technical mixtures by isomer-specific determination using their synthetic standards in SIM mode with GC-MS and two new diastereomeric isomers. Chemosphere 2008, 70, 1961-1972.

(33) Routledge, E. J.; Sumpter, J. P. Estrogenic activity of surfactants and some of their degradation products assessed using a recombinant yeast screen. Environ. Toxicol. Chem. 1996, 15, 241-248.

(34) Routledge, E. J.; Sumpter, J. P. Structural features of alkylphenolic chemicals associated with estrogenic activity. J. Biol. Chem. 1997, 272, 3280-3288.

(35) Brzozowski, A. M.; Pike, A. C.; Dauter, Z.; Hubbard, R. E.; Bonn, T.; Engstrom, O.; Ohman, L.; Greene, G. L.; Gustafsson, J. A.; Carlquist, M. Molecular Basis of agonism and antagonism in the oestrogen receptor. Nature 1997, 389, 753-758.

(36) Fang, H.; Tong, W.; Shi, L. M.; Blair, R.; Perkins, R.; Branham, W.; Hass, B. S.; Xie, Q.; Dial, S. L.; Moland, C. L.; Sheehan, D. M. Structure-activity relationships 
1 for a large diverse set of natural, synthetic, and environmental estrogens. Chem.

2 Res. Toxicol. 2001, 14, 280-294.

3 
1 TABLE 1. Degradation of tNP by S. xenophagum Bayram in minimal medium. The

2 degradation of individual isomers correlated well with their assignment to one of the six

3 mass spectrometrical groups (Group $1>$ Group $2>$ Group $3>$ Group $5>$ Group $6>$

4 Group 4). Isomers are listed according to the amount degraded [\%].

\begin{tabular}{|c|c|c|c|c|c|c|c|}
\hline $\begin{array}{l}\text { Peak in } \\
\text { Figure } 2\end{array}$ & $\begin{array}{c}\mathrm{NP} \\
\text { isomer }\end{array}$ & $\begin{array}{c}\text { Reten- } \\
\text { tion } \\
\text { time } \\
\text { [min] } \\
\text { (Figures } \\
\text { 2A and } \\
\text { S1A) }\end{array}$ & Structure & $\begin{array}{c}\text { Mass } \\
\text { spectro- } \\
\text { metrical } \\
\text { group } \\
(5,31)\end{array}$ & $\begin{array}{c}\text { Degra- } \\
\text { dation } \\
\text { after } \\
9 \text { days } \\
\text { of } \\
\text { incuba- } \\
\text { tion } \\
{[\%]}\end{array}$ & $\begin{array}{l}\text { Corres- } \\
\text { ponding } \\
\text { peak in } \\
\text { ref. (32) }\end{array}$ & $\begin{array}{c}\text { Corres- } \\
\text { ponding } \\
\text { peak in } \\
\text { refs. }(5 \text {, } \\
31)\end{array}$ \\
\hline 14 & $\mathrm{NP}_{128}$ & 34.8 & & 1 & 99.7 & $3(\mathrm{D})$ & 5 \\
\hline 26 & $\mathrm{NP}_{119}$ & 37.0 & & 1 & 99.7 & $6(\mathrm{I})$ & 10 \\
\hline 9 & $\mathrm{NP}_{38}$ & 34.1 & & 1 & 99.3 & $3\left(C^{\prime}\right)$ & 3 \\
\hline 7 & $\mathrm{NP}_{36}$ & 33.7 & & 1 & 98.8 & 2 (B) & 2 \\
\hline 13 & $\mathrm{NP}_{112}$ & 34.5 & & 2 & 98.2 & $3(\mathrm{C})$ & $4 B$ \\
\hline 31 & $\mathrm{NP}_{35}$ & 38.7 & & 1 & 97.6 & $10(\mathrm{M})$ & 14 \\
\hline 16 & $\mathrm{NP}_{37}$ & 35.19 & & 1 & 96.6 & $4(F)$ & 7 \\
\hline 33 & $\mathrm{NP}_{9}$ & 38.91 & & 1 & 96.1 & $11(\mathrm{O})$ & 17 \\
\hline 17 & $\mathrm{NP}_{111 \mathrm{a}}$ & 35.25 & & 2 & 94.0 & $4(\mathrm{E})$ & 6 \\
\hline 19 & $\mathrm{NP}_{111 \mathrm{~b}}$ & 35.7 & & 2 & 90.4 & $5(\mathrm{G})$ & 8 \\
\hline
\end{tabular}




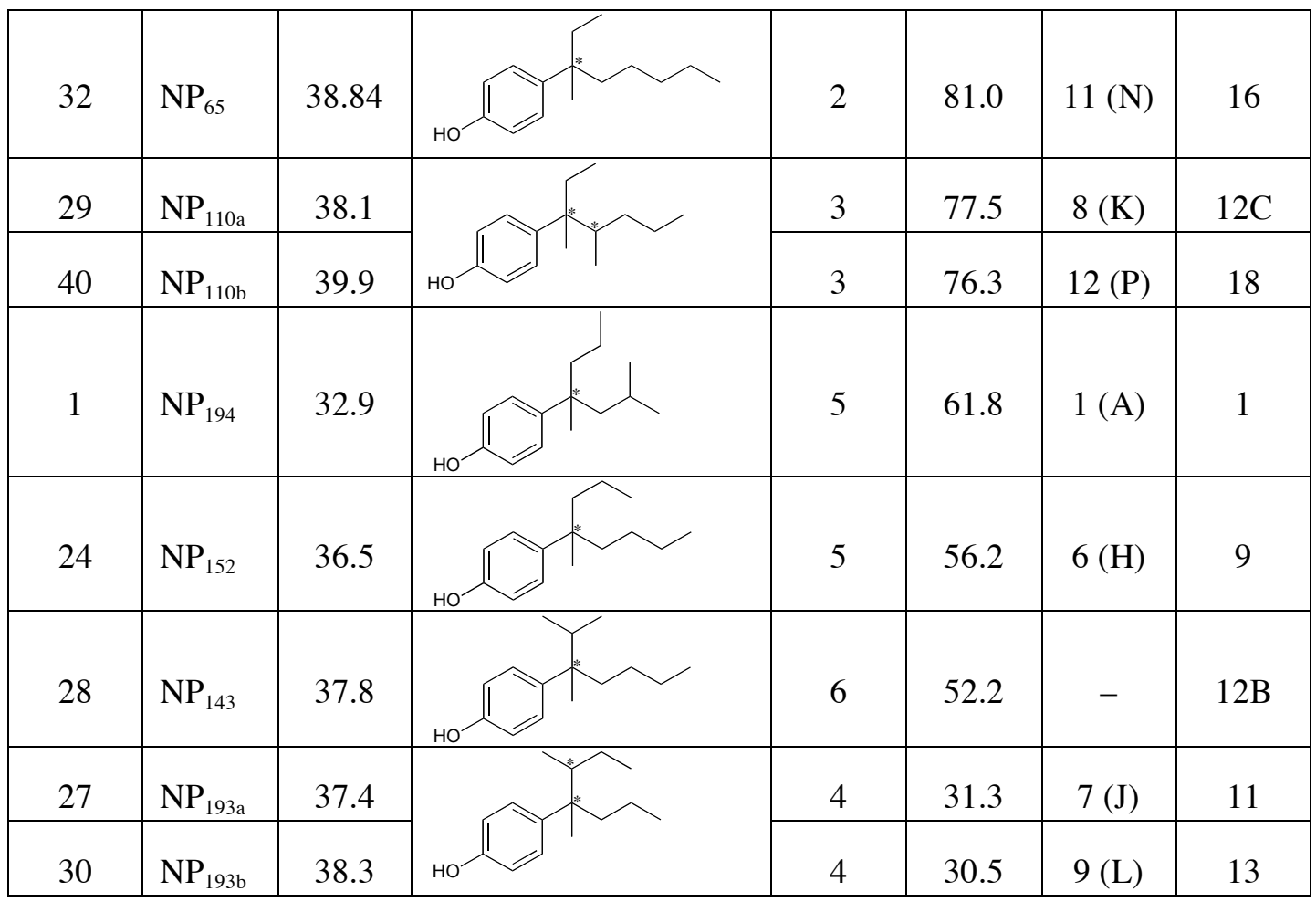


1 TABLE 2. Structures and estrogenicities of $17 \beta$-estradiol and NP isomers assayed in

2 this as well as other studies (20-22). Potencies relative to that of the technical mixture

3 are shown. In the cases where the test samples represented mixtures of two isomers, we

4 also pointed out the minor component and the relative abundances. The test assay and

5 the tNP mixture used in the different studies, and the relevant concentrations to

6 determine relative potencies are indicated.

\begin{tabular}{|c|c|c|c|c|c|c|}
\hline $\begin{array}{c}\text { Test } \\
\text { compound }\end{array}$ & $\begin{array}{l}\text { Main } \\
\text { chain } \\
\text { length }\end{array}$ & Structure & $\begin{array}{c}\text { Kim } \\
\text { et al. } 2004 \\
\quad(20)\end{array}$ & $\begin{array}{c}\text { Shioji } \\
\text { et al. } 2006 \\
(22)\end{array}$ & $\begin{array}{c}\text { Preuss } \\
\text { et al. } \\
2006 \\
(21)\end{array}$ & This study \\
\hline $\begin{array}{c}\text { Estrogenicity } \\
\text { assay }\end{array}$ & & & YES & $\begin{array}{c}\text { Yeast Two- } \\
\text { Hybrid Assay } \\
\end{array}$ & MVLN & YES \\
\hline $\begin{array}{l}\text { Commercial } \\
\text { source of tNP }\end{array}$ & & & $\begin{array}{l}\text { Tokyo Kasei } \\
\text { Koygo Co. }\end{array}$ & Kishida & Fluka & $\begin{array}{c}\text { Schenectady } \\
\text { International, } \\
\text { Inc. }\end{array}$ \\
\hline $\begin{array}{c}\text { Concentrations } \\
\text { used to } \\
\text { calculate } \\
\text { relative } \\
\text { potencies } \\
\end{array}$ & & & $\begin{array}{l}\text { Minimal } \\
\text { effective } \\
\text { concentrations }\end{array}$ & $\begin{array}{c}\text { concentrations } \\
\text { producing } \\
\text { same effect as } \\
\mathrm{EC}_{10} \text { of } \mathrm{E}_{2} \\
\end{array}$ & $\begin{array}{c}\mathrm{EC}_{20} \\
\text { of test } \\
\text { compounds }\end{array}$ & $\begin{array}{l}\text { concentrations } \\
\text { producing } \\
\text { same effect as } \\
\mathrm{EC}_{50} \text { of } \mathrm{E}_{2} \\
\end{array}$ \\
\hline & & & \multicolumn{4}{|c|}{ Relative potencies } \\
\hline $\begin{array}{c}17 \beta- \\
\text { Estradiol }\end{array}$ & & & 54825 & 538 & 84615 & 3168 \\
\hline $\begin{array}{l}\mathrm{NP}_{93} \\
(81 \%)\end{array}$ & 5 & & - & - & - & 1.87 \\
\hline $\begin{array}{l}\mathrm{NP}_{95} \\
(17 \%)\end{array}$ & 5 & & & & & \\
\hline $\begin{array}{c}\mathrm{NP}_{70 \mathrm{a}} \\
(43.1 \%) \\
\mathrm{NP}_{70 \mathrm{~b}} \\
(40.5 \%) \\
\end{array}$ & 6 & & - & - & - & 1.68 \\
\hline techn. NP & & & 1.00 & 1.00 & 1.00 & 1.00 \\
\hline $\begin{array}{l}\mathrm{NP}_{111 \mathrm{a}} \\
(44.9 \%) \\
\mathrm{NP}_{111 \mathrm{~b}} \\
(55.1 \%)\end{array}$ & 5 & & - & - & 0.81 & 0.78 \\
\hline $\mathrm{NP}_{152}$ & 5 & & 1.09 & 0.080 & - & 0.70 \\
\hline
\end{tabular}




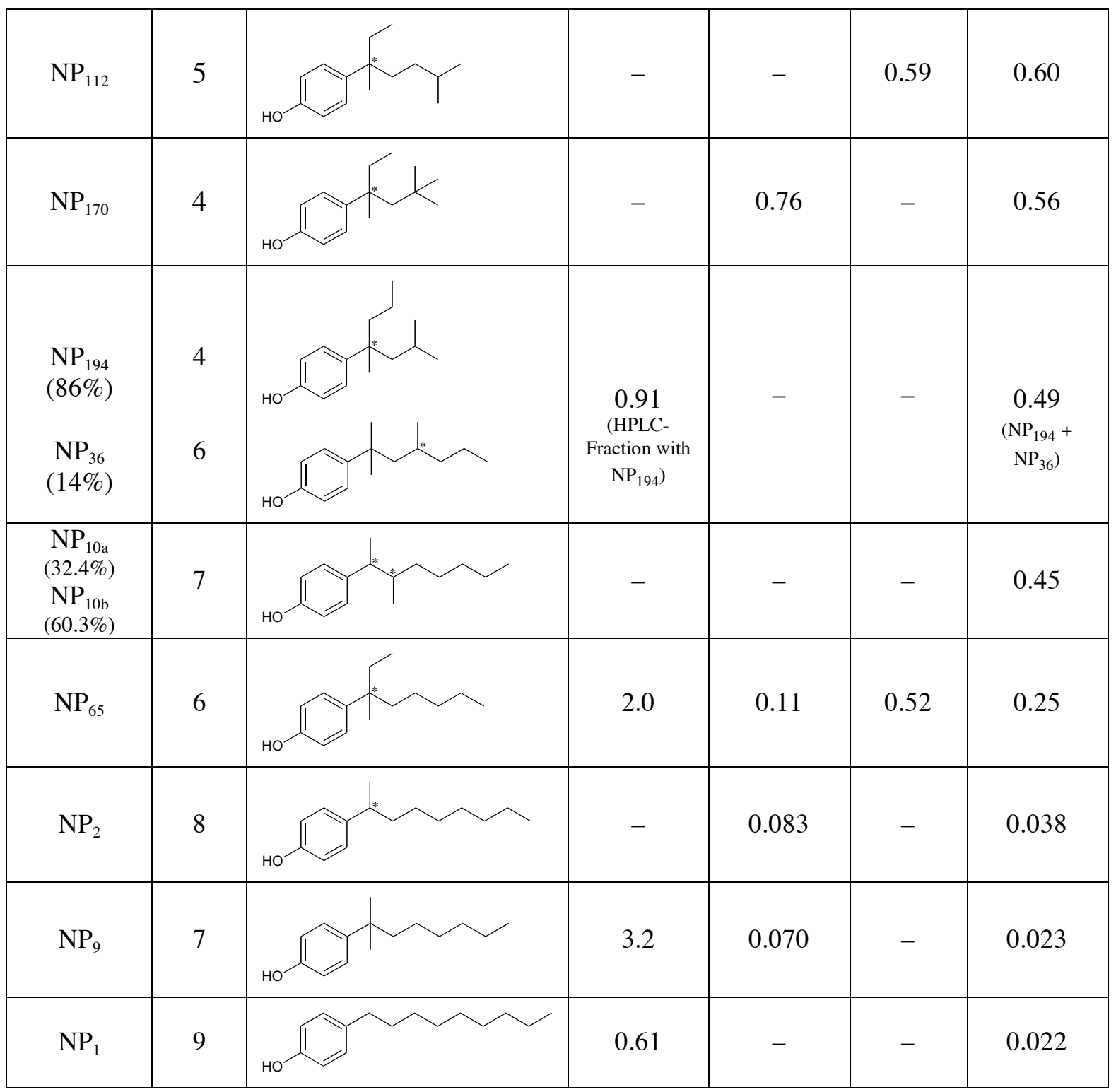


1 TABLE 3. Effects of $\beta$ - and $\gamma$-substituents on estrogenicity: Comparison of $\beta$ - and $\gamma$ -

2 substituted NPs serving as references (acronyms in bold and italic), with structurally

3 related isomers (A-D). Reference isomers can be derived from related isomers by

4 shifting of a group to the $\beta$ - and $\gamma$-position (abstraction and relocation of the migrating

5 group are indicated by wavelines and arrows, respectively). Besides positive effects of

$6 \beta$ - and $\gamma$-substituents, the increase in estrogenicity associated with the transposition

7 might also be explained by negative effects (column at the far right). The clear potency

8 difference between $\mathrm{NP}_{65}$ and $\mathrm{NP}_{112}$ seems to indicate that also $\delta$-substituents have a

9 positive effect on estrogenicity (D).

10

11

\begin{tabular}{|c|c|c|c|c|c|c|c|c|}
\hline & NP isomer & $\begin{array}{l}\text { main } \\
\text { chain } \\
\text { length }\end{array}$ & $\alpha$ & $\beta$ & $\gamma$ & $\delta$ & $\begin{array}{l}\text { Rela- } \\
\text { tive } \\
\text { Poten- } \\
\text { cy }\end{array}$ & $\begin{array}{c}\text { Possible } \\
\text { negative } \\
\text { effect }\end{array}$ \\
\hline \multicolumn{9}{|c|}{ (A) Effect of $\beta$-substituents } \\
\hline$N P_{10}$ & & 7 & $\mathrm{Me}$ & $\mathrm{Me}$ & & & 0.45 & \\
\hline $\mathrm{NP}_{9}$ & & 7 & $\begin{array}{l}\text { di- } \\
\mathrm{Me}\end{array}$ & & & & 0.023 & $\begin{array}{c}\text { Bulkiness } \\
\text { adjacent } \\
\text { to the } \alpha- \\
\text { position }\end{array}$ \\
\hline \multicolumn{9}{|c|}{ (B) Effect of bulky $\beta$-substituents } \\
\hline$N P_{70}$ & & 6 & $\mathrm{Me}$ & Et & & & 1.68 & \\
\hline $\mathrm{NP}_{10}$ & & 7 & $\mathrm{Me}$ & $\mathrm{Me}$ & & & 0.45 & $\begin{array}{l}\text { long main } \\
\text { chain }\end{array}$ \\
\hline $\mathrm{NP}_{65}$ & & 6 & $\begin{array}{c}\mathrm{Me}, \\
\mathrm{Et}\end{array}$ & & & & 0.25 & $\begin{array}{c}\text { bulky } \alpha- \\
\text { substi- } \\
\text { tuent }\end{array}$ \\
\hline $\mathrm{NP}_{2}$ & & 8 & $\mathrm{Me}$ & & & & 0.038 & $\begin{array}{l}\text { long main } \\
\text { chain }\end{array}$ \\
\hline
\end{tabular}




\begin{tabular}{|c|c|c|c|c|c|c|c|c|}
\hline \multicolumn{9}{|c|}{ (C) Effect of $\beta$ - or $\gamma$-substituents } \\
\hline $\begin{array}{l}\boldsymbol{N P}_{\mathbf{9 3}_{3}} \\
(81 \%)\end{array}$ & & 5 & $\begin{array}{l}\text { di- } \\
\mathrm{Me}\end{array}$ & $\mathrm{Me}$ & & $\mathrm{Me}$ & \multirow{2}{*}{1.87} & \\
\hline $\begin{array}{l}\boldsymbol{N P}_{95} \\
(17 \%)\end{array}$ & & 5 & $\begin{array}{l}\mathrm{di}- \\
\mathrm{Me}\end{array}$ & & $\mathrm{Me}$ & $\mathrm{Me}$ & & \\
\hline $\mathrm{NP}_{112}$ & & 5 & $\begin{array}{c}\mathrm{Me} \\
\mathrm{Et}\end{array}$ & & & $\mathrm{Me}$ & 0.60 & $\begin{array}{c}\text { bulky } \alpha- \\
\text { substi- } \\
\text { tuent }\end{array}$ \\
\hline \multicolumn{9}{|c|}{ (D) Effect of $\gamma$-substituents } \\
\hline$N P_{111}$ & & 5 & $\begin{array}{c}\mathrm{Me}, \\
\mathrm{Et}\end{array}$ & & $\mathrm{Me}$ & & 0.78 & \\
\hline $\mathrm{NP}_{152}$ & & 5 & $\begin{array}{l}\mathrm{Me} \\
\mathrm{Pr}\end{array}$ & & & & 0.70 & $\begin{array}{c}\text { bulky } \alpha- \\
\text { substi- } \\
\text { tuent }\end{array}$ \\
\hline $\mathrm{NP}_{112}$ & & 5 & $\begin{array}{c}\mathrm{Me} \\
\mathrm{Et}\end{array}$ & & & $\mathrm{Me}$ & 0.60 & \\
\hline $\mathrm{NP}_{65}$ & & 6 & $\begin{array}{c}\text { Me, } \\
\text { Et }\end{array}$ & & & & 0.25 & \\
\hline
\end{tabular}


1 FIGURE 1 . Diverging pathways in the metabolism of an $\alpha$-quaternary $\left(\mathrm{NP}_{112}\right)(\mathrm{A})$ and

2 an $\alpha$-tertiary $\mathrm{NP}$ isomer $\left(\mathrm{NP}_{2}\right)(\mathrm{B})$ by strain Bayram $(8,13,15)$. In both cases, the initial

3 reaction is an ipso-hydroxylation, which yields 4-alkyl-4-hydroxycyclohexa-2,5-dien-1-

4 one intermediates (quinols). Because of unsufficient stabilization by $\alpha$-substitution, the

5 alkyl moiety of $\alpha$-tertiary alkyl-cyclohexadienones is not released as a cation. Hence, $\alpha$ -

6 tertiary quinol intermediates accumulate and undergo side-reactions, e.g. a dienone-

7 phenol rearrangement (NIH-shift)(13)(B). Bold, thin, and dotted reaction arrows

8 symbolize putatively high, medium sized, and low reaction rates, respectively.

9

10 FIGURE 2. "Aging” of tNP as a result of degradation by Sphingobium xenophagum

11 Bayram in minimal medium. GC-MS chromatograms (TIC) of the culture extracts

12 correspond to the start of the experiment (A) and to day 9 of the incubation (B). Please

13 note that differential degradation leads to a significant change in the isomers

14 distribution of the NP mixture. Chromatograms of extracts from cultures sacrificed at 9

15 (duplicate), 18, and 27 days were nearly identical (B), indicating that no further

16 degradation occurred after 9 days. In contrast, the isomer pattern in the noninoculated

17 control was identical to that of nondegraded technical NP (A). Peaks of recalcitrant

18 isomers (Groups 4, 6, and 5) are highlighted (encircled numbers). The great majority of

19 peaks eluting before peak 1 most likely correspond to ortho-isomers $(5,31)$. Signals

20 were numbered according to their retention time (Figures S1A and B). The vertical

21 position of a mass spectrometrical group indicates the recalcitrance of its members to

22 biodegradation by strain Bayram (Group numbers - encircled numbers at the far right

23 - are listed according to increased recalcitrance). 
1 FIGURE 3. Response of the yeast estrogen screen (YES) to a range of NP isomers. The

2 graph depicts the logarithmic concentration of $17 \beta$-estradiol $\left(\mathrm{E}_{2}\right)$ serially diluted from

$32.5 \mathrm{nM}$ to $4.9 \mathrm{pM}$ and of NP isomers diluted from $0.13 \mathrm{mM}$ to $0.24 \mu \mathrm{M}$, plotted against

4 the absorbance of the medium after a 3-day incubation at $32{ }^{\circ} \mathrm{C}$. The blank (BL) shows

5 the response of the assay in the absence of test compound (solvent alone; blanks run in

6 parallel to $\mathrm{E}_{2}$-assays are shown). Values represent mean \pm standard deviation from

7 duplicate wells. Structures of selected test compounds are shown. The vertical lines

8 depict the concentrations used to determine the potencies of $\mathrm{NP}_{93}, \mathrm{NP}_{1}$ (the most and

9 least potent isomers of our test series, respectively; Table 2), and $17 \beta$-estradiol, relative

10 to that of tNP. The relative potency of a test NP isomer was assessed by dividing the

11 concentration of $\mathrm{tNP}$ producing an $\mathrm{OD}$ of $1.737\left(\mathrm{EC}_{50}\right.$ of $17 \beta$-estradiol) by that of the

12 test isomer effecting the same response.

13 


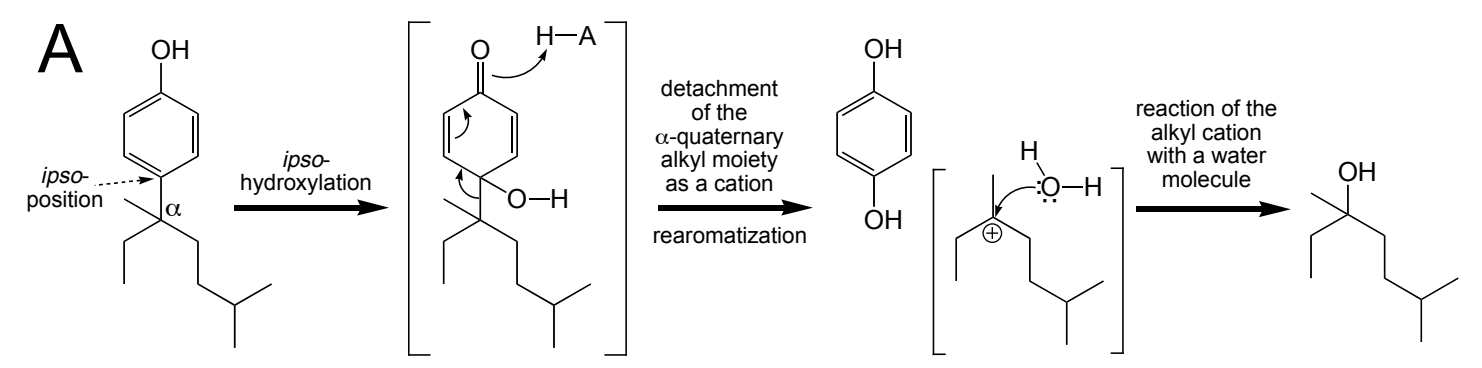

B
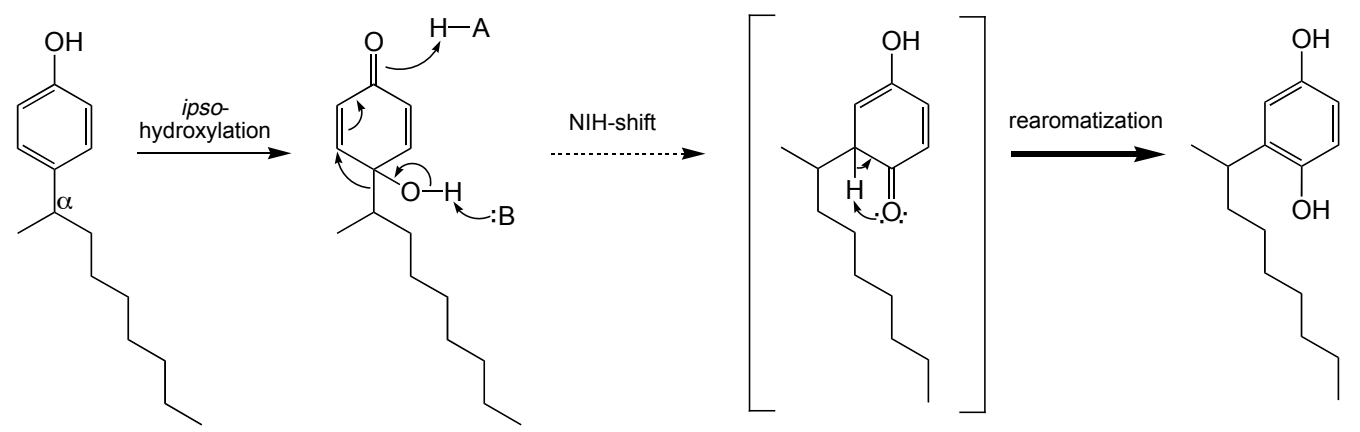

\section{FIGURE 1}

3 


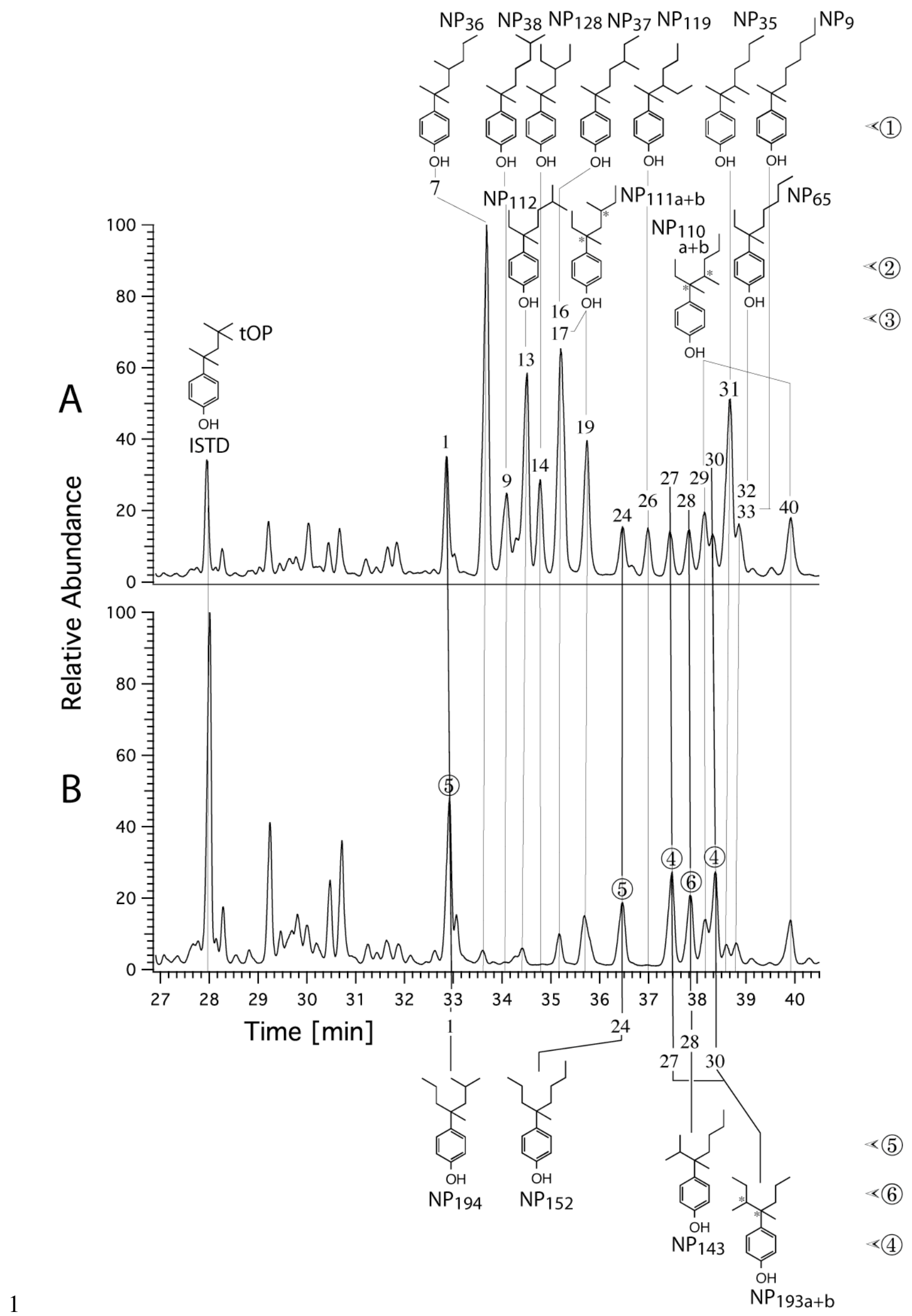

2 FIGURE 2 


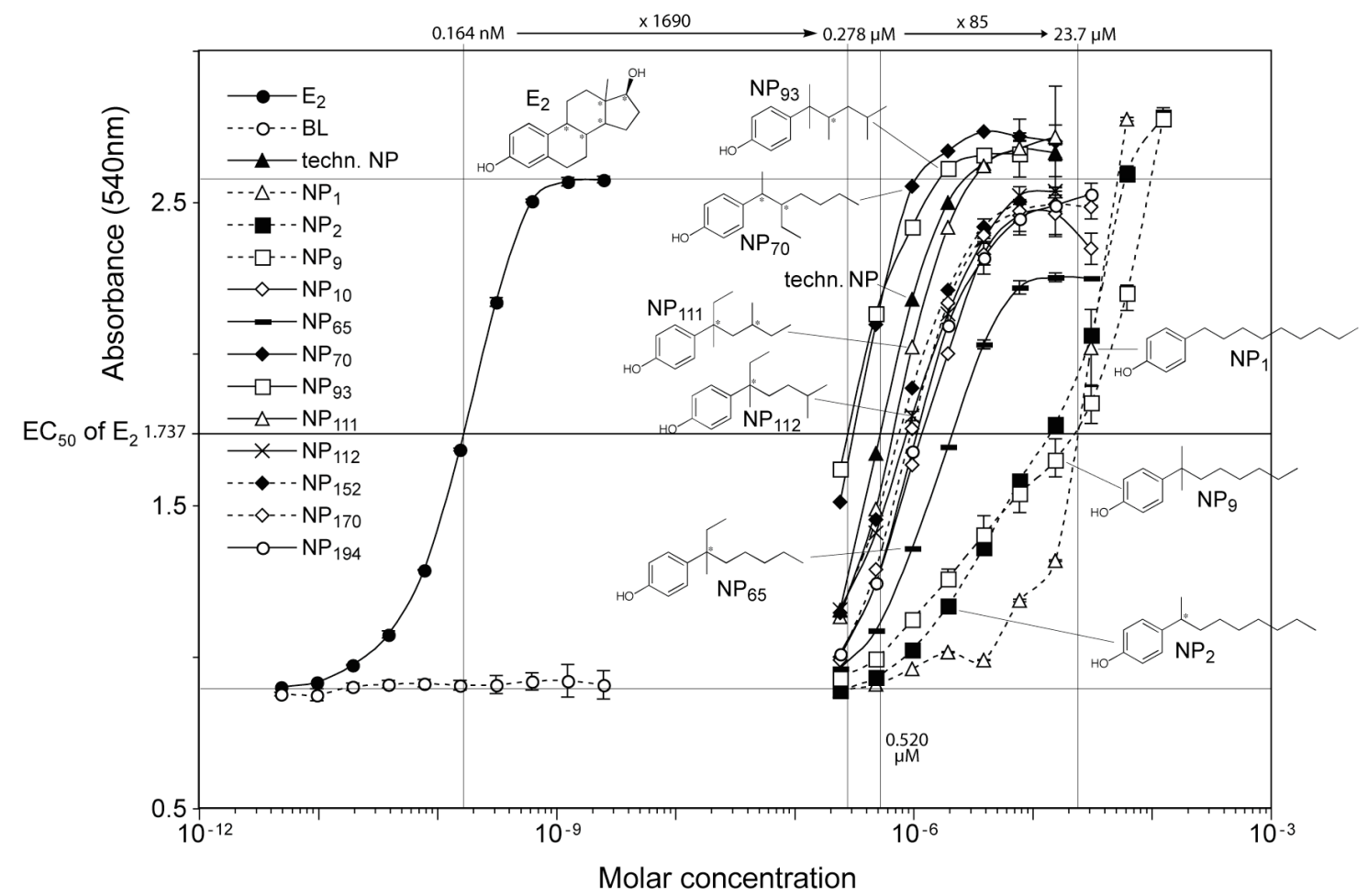

1

2 FIGURE 3

3 
1 "Brief" for Table of content:

2

3

4 Degradation of endocrine disrupting nonylphenols by microbial ipso-substitution

5 markedly reshapes isomer distribution patterns and thus might alter the specific

6 estrogenicity of aging material. 